\title{
A Scientific Approach and Data Analysis of Chemicals used in Packed Juices
}

\author{
Mr. Dharmesh Dhabliya \\ VIIT Pune \\ dharmeshdhabliya@gmail.com
}

Abstract:

Centrifugation is one of the principal unit activities in the sugar business. Customarily it is utilized in the wake of thickening of the stick juice, for example at an extremely high thickness extend. The creators are of the view that a sedimentation axis will have the most appropriate. The structure highlights of centrifugals from cluster to consistent sorts have been concentrates widely, their operational boundaries have additionally been talked about with down to earth application by a few specialists. Aside from centrifugation, the mechanical partition additionally assumes a critical job for evacuating polluting influences acquire a nearly cleansed item, Screening is likewise a technique utilized in different structures in the sugar business. The speed keeps up could be around $8000 \mathrm{rpm}$ in the scope of $70-75 \%$ mud dampness. The parchment transport in this kind of axis can capture suspension particles. The size scope of $1-2 \mu \mathrm{m}$. It can have a wide scope of feed stream, which can be assessed based on a full-scale. Every one of these focuses as examined for a helpful reception of centrifugation of stick juice in the sugar business.

Keywords; Sugar, Cane juice, Centrifugation, etc.

\section{INTRODUCTION}

The determination of rotator for the particular kind of suspension needs some essential information. The particles, which are available in various sizes, their dissemination in the medium, powerful consistency, thickness and so on are the principle rules. The writing uncovers that centrifugation of can juice was done route in 1917 however hardly any procedure subtleties are accessible. A ceaseless transport release rotator, which is fundamentally a parchment type, gathers suspended solids by sedimentation mud persistently evacuates the fluid through discrete outlets. It comprises of a basic screw type transport which expels the kept solids. The information on such a unit activity has been used in the current investigation. The juice is exposed to centrifugation legitimately in the wake of processing of the stick. This treatment has been thought of especially to explain squeezes by expelling the suspended particles, viz. silica, natural salts, and so on alongside mud. Likewise the colloidal particles can likewise be isolated out and the shading factor in this way at first improved. This treatment fundamentally cuts down the compound burden on the juice on its approach to explanation. 

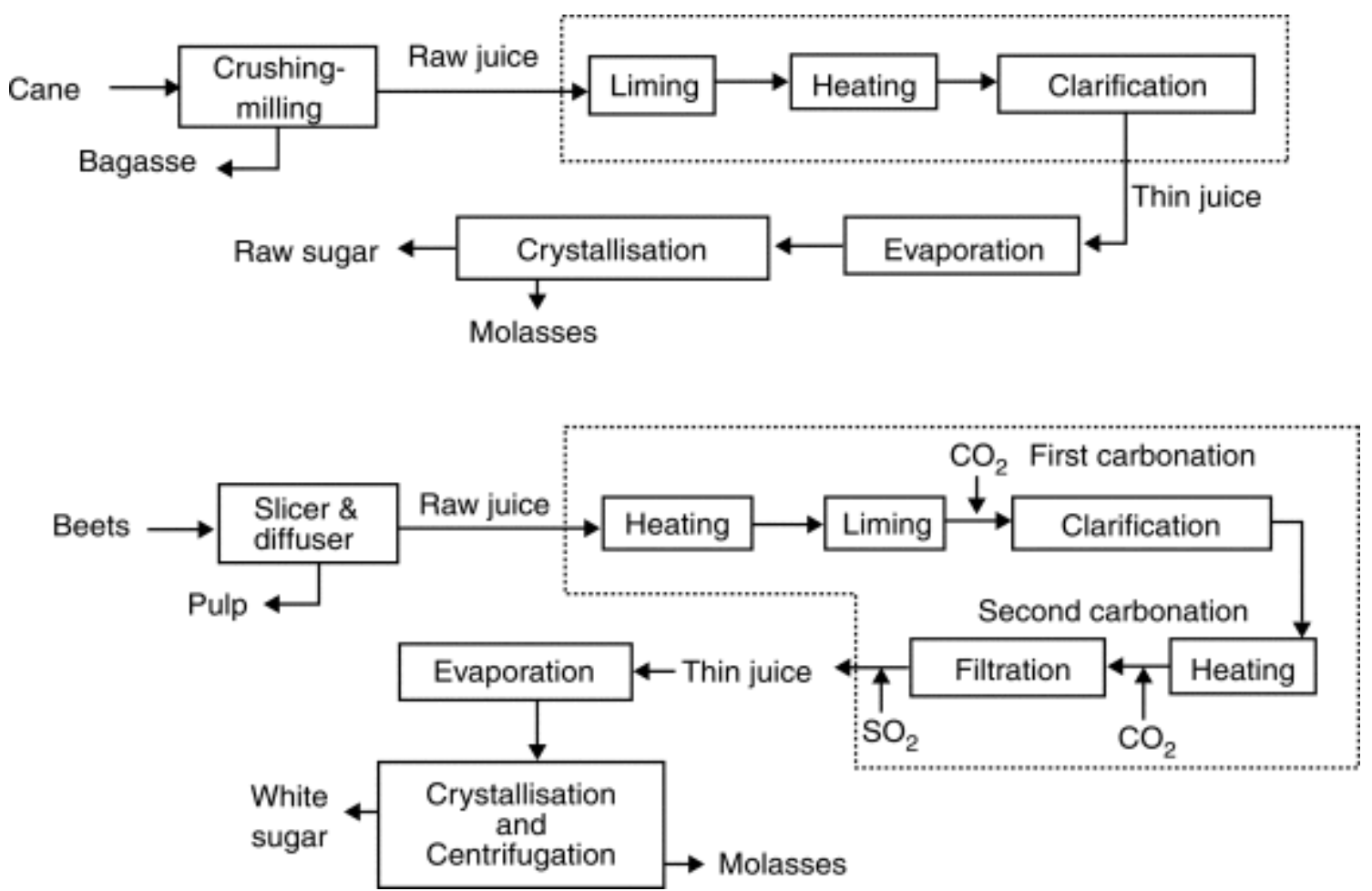

fig 1: cane juice centrifugation in sugar industry

\section{CANE JUICE CENTRIFUGATION}

Cane juice can be regarded as a suspension. Hence, solid-liquid separation could be made possible by increasing the gravitational force in a centrifugal separator. Sedimentation centrifuges are based on the principle of density difference. For industrial purposes, they can be designed on the basis of data collected in a laboratory bottle centrifuge. These data provide a better say for scaling-up to commercial centrifuges for cane juice treatment by calculating the theoretical capacity sector, i.e. using the sigma concept:

The $\Sigma$ value in sq.ft. for a bottle centrifuge is given by the equation

$$
\Sigma=\mathrm{Wv} / * 2 \mathrm{~g}(\operatorname{In} 2 \mathrm{r} 1 / \mathrm{r} 1+\mathrm{r} 2)]
$$

where

$\mathrm{r} 1=$ the radius in $\mathrm{ft}$ from the centrifuge axis to the liquid surface when the bottle is spinning. $\mathrm{r} 2=$ the radius to the bottom of the bottles

$\mathrm{w}=$ angular velocity of rotary motion (radians/sec).

$v=$ volume of the sample (cu.ft)

$\mathrm{g}=$ gravitational acceleration $\mathrm{ft} / \mathrm{sec}^{2}$. 
Furthermore, the value of $\mathrm{Q} / \sum$ can also be calculated using the following expression:

$$
\mathrm{Q} / \sum=2 \mathrm{~g} \operatorname{In}(2 \mathrm{r} 1 / \mathrm{r} 1+\mathrm{r} 2) / \mathrm{w}^{2} \mathrm{t}
$$

where

$\mathrm{Q}=$ flow rate in cu.ft/sec through the

centrifuge, and $\mathrm{t}=$ observed

sedimentation time required in seconds.

The preliminary calculations for the proposed machines are based on the information gatered from a bottle centrifuge or a laboratory model.

Another improvement factor is the residual moisture content. The variation range of this value is quite noticeable. The value is greatly influenced by the $\mathrm{g}$ factor. Haruni predicted the following

empirical relation:

$$
\mathrm{R}-\mathrm{Rm}=\mathrm{C}(\mathrm{Nm}-\mathrm{N})^{\mathrm{a}}
$$

where

$\mathrm{R}=$ residual moisture content ( $\mathrm{g} / \mathrm{g}$ dry solids) obtained at $\mathrm{N} \mathrm{rpm}$

$\mathrm{Rm}=$ residual moisture found by spinning at the deposition speed $\mathrm{Nm} \mathrm{C}$ and a are empirical constants valid only when $\mathrm{Nm}>\mathrm{N}$.

\section{DATA ANALYSIS}

It is quite interesting to note from Table I that the centrifugal effect on the purity is negligible. This clearly reveals that suspended particles along with organic salts are discharged with the mud whereas it fails to affect the dissolved solids. Secondly, $\mathrm{pH}$ and temperature almost remain the same, It is obvious that no chemical change is taking place. The temperature rise of $1^{0} \mathrm{C}$ may be due to the closed centrifuge chamber and resultant restricted heat dissipation, regarding the rpm and degree of separation, i.e. attainable $\mathrm{g}$ at the bottle tip, both factors will have to be optimized when switching over to a commercial scale as discussed in the earlier part. 
Table I

\begin{tabular}{|l|c|c|c|c|c|}
\hline MEDIUM & $\begin{array}{l}\text { PURI } \\
\text { TY }\end{array}$ & PH & $\begin{array}{l}\text { TEMPERATU } \\
\text { RE, }\end{array}$ & $\begin{array}{l}\text { SPEED, } \\
\text { RPM }\end{array}$ & $\begin{array}{l}\text { ATTAINABLE } \\
\text { G' }\end{array}$ \\
\hline $\begin{array}{l}\text { CANE } \\
\text { JUICE }\end{array}$ & 76.2 & $4.7-5.0$ & 32 & - & - \\
\hline TREATED & & & & & \\
\hline JUICE & 75.3 & $4.6-5.0$ & 33 & 6200 & 2200 \\
\hline
\end{tabular}

On examining Table II, the reduction in relative viscosity is approximately $20 \% \pm 5.0 \%$. The mixed juice may be treated as a suspension. And this reduction may be attributed to the change in concentration of the medium. Finally, the physical appearance of the treated juice is quite brilliant with a tinge of turbidity containing a small amount of floating bagacillo. Around 20\% ICUMSA units in colour improvement is evident from Table II, The ICUMSA colour of clear juice of the same factory where the said experiments were carried out was also measured and this value was found to be quite near to the value for treated juice. In Indian conditions, the dirt correction plays an important factor in the analysis of the sugar balance. Instead of the conventional method, if the centrifuged juice is directly weighed, the sugar balance report could be made more accurate. This is an additional advantage of the treatment.

\section{Table II}

\begin{tabular}{|c|c|c|c|}
\hline MEDIUM & $\begin{array}{c}\text { VISCOSITY } \\
\text { CPS }\end{array}$ & $\begin{array}{c}\text { CLARIT } \\
\text { Y }\end{array}$ & ICUMSA UNITS \\
\hline CANE JUICE & 1.26 & 42.8 & 4210.00 \\
\hline $\begin{array}{c}\text { TREATED } \\
\text { JUICE }\end{array}$ & 1.05 & 13.6 & 3256.00 \\
\hline CLEAR JUICE & 1.03 & 10.5 & 2865.00 \\
\hline
\end{tabular}

\section{CONCLUSION}

In this paper we have talked about centrifugation of stick juice. The operational boundaries, for example, evacuation of suspended particles, clearness and ICUMSA 
shade of the centrifuged juice, soil adjustment and focal points of the procedure have been intricately examined.

\section{REFERENCES}

[1] Premalatha M (2008) Efficient cogeneration scheme for sugar industry. Journal of Scientific \& Industrial Research 67:239-242

[2] Birru (2007) Investigation of the potential of sugar cane industries (MSc thesis)

[3] Marianela Cordovés Herrera(1999)."CaneSugar and The environment-Cuba conference". Available at http://www.fao.org/docrep/005/X4988E/x4988e01.htm. Accessed March 2012

[4] Ingaramo A, Heluane H, Colombo M, Cesca M (2009) Water and wastewater eco-efficiency indicators for the sugar cane industry.Journal of Cleaner Production 17 : 487-495

[5] Kamate CS and Gangavati BP (2009) Cogeneration in Sugar Industries: Technology Options and Performance Parameters-A Review, Cogeneration \& Distributed Generation Journal, 24:4, 633, DOI:10.1080/15453660909595148

[6] Raghu RJ, Banerjee R(2003)Energy and cogeneration targeting for a sugar factory. Applied Thermal Engineering 23:1567-1575

[7] Ensinas VA, Lozano MA, Serra LM (2007) Analysis of process steam demand reduction and electricity generation in sugar and ethanol production from sugarcane. Energy conversion \& Management 48:2978-2987

[8] Lavarack BP, Hodgson JJ, Broadfoot R, Vigh,S and Venning J (2004) Improving the energy efficiency of sugar factories: Case study for pioneer mill Proc. Aust. Soc. Sugar Cane Technology: 26

[9] ABB (2010) ACS 1000 variable speed drives increase energy efficiency at sugar plant-case study. Available http://www05.abb.com/global/scot/scot216.nsf/veritydisplay/46ae6cf38fa1228bc12577e40056e2 1d/\$file/CS_Sugar\%20RevB_lowres.pdf

[10] Dias SOM, Modesto M, Ensinas VA, Nebra AS, Filho MR, Rossell VEC (2011) Improving bioethanol production from sugarcane: evaluation of distillation, thermal integration and cogeneration systems. Energy 36:6, 3691-3703

[11] Solomon S (2011) The Indian Sugar Industry: An Overview. Sugar Technology 13(4):255-265

[12] Keerthipala RA (2007) Sugar Industry of Sri Lanka: Major Issues and Future Directions for Development. Sugar Technology :9(1) 1-10

[13] Ethiopian sugar corporation. Available at http://www.etsugar.gov.et/

[14] Alonso-Pippo W, Luengo AC, Koehlinger J, Garzone P, Cornacchia G (2008) Sugarcane energy use- The Cuban case. Energy Policy $36: 2163-2181$

[15] Edward D (1981)Standard Fabrication Practices for Cane Sugar Mills. Amsterdam: Elsevier Scientific Pub. Co. ; New York: Elsevier Scientific Pub. Co. ; New York: Elsevier Scientific Pub. Co. ISBN0-444-41958-6;ISBN1-322-26407-4;ISBN1-4832-8967-2

[16] Costa, A. F. S.; Nascimento, V. R.; Amorim, J. D. P.; Gomes, E. A. S.; Araujo, L. M.; Sarubbo, L. A. Residue from the production of sugar cane: an alternative nutrient used in biocellulose production by Gluconacetobacter hansenii. Chemical Engineering Transactions, v. 64, p. 7-12, 2018. DOI: $10.3303 /$ CET1864002

[17] Hamerski, F. Study of variables in the process of carbonation of the broth of sugar cane. p. 148. Dissertation. Graduate degree in food technology. Federal University the Paraná, Curitiba, 2009. 